\title{
ESTADO E AGRICULTURA GAÜCHA NA REPÚBLICA NOVA
}

Ema Júlia Massera Aroztegui *

\section{1 - INTRODUÇÃO}

O objetivo do presente trabalho é pesquisar a atuação política e sindical dos empréstimos arrozeiros e a politica do Estado em relação à produção rizícola que era, na época, a única produção agrária capitalista rio-grandense.

Em 1930, a cultura arrozeira ocupava $4 \%$ das terras agrícolas do estado, utilizava vultosos capitais e, em época de colheita, empregava 30.000 trabalhadores. Durante a República Nova,cresceu a importância da rizicultura no contexto gaúcho, principalmente pelo aumento de seu peso nas exportações. Em 1934 , o arroz já ocupa o $2^{\circ}$ lugar entre os produtos de exportação ordenados pelo seu valor.

Daí a necessidade do estudo que agora apresentamos, como parte de um projeto de pesquisa mais amplo que vem analisando a economia gaúcha entre 1930 e 1960.

\section{2 - PRODUÇÃO ARROZEIRA, SINDICATO E ESTADO NOS MARCOS DA REPÜBLICA VELHA}

No começo do século XX, com os primeiros investimentos em irrigação e mão-de-obra assalariada, iniciou-se a rizicultura capitalista gaúcha. Tendo como centros os municípios de Cachoeira - lider indiscutivel da produção pelo menos até a década de 1930 - , Porto Alegre e Pelotas, o cultivo expandiu-se pela Depressão Central e litoral da Lagoa dos Patos e, na década de 1940 , em direção à fronteira sudoeste do estado.

Entre inícios do século e 1921, os preços do arroz haviam dado margem a uma considerável Renda Diferencial da terras nas várzeas irrigadas do estado. Graças à política federal de valorização do café, que determinou o fechamento das importações de arroz, os mercados de consumo nacionais funcionavam, em exclusivo proveito dos produtores brasileiros do ceral. No caso da rizicultura gaúcha, o mercado local foi muito mais importante que o nacional. Mais do que isso, a Primeira Guerra Mundial permitiu aos gaúchos concorrer exitosamente com espanhóis e italianos na área do Rio da Prata,onde os mercados eram parti- 
cularmente apropriados às condições de preço e qualidade do superior arroz rio-grandense, fazendo que essa região se tornasse o principal mercado de nosso arroz.

Gaúchos das mais variadas origens lançavam-se a lucrar com a nova rique$\mathrm{za}$, mas as características da acumulação capitalista rio-grandense - latifúndio, acumulação na charqueada e no comércio de produtos agrícolas coloniais determinaram a formação de uma estrutura produtora e comercializadora, onde um reduzido núcleo de elementos de origem urbana - entre os quais se destacam os comerciantes e industriais de ascendência germânica - e os fazendeiros donos da terra se colocavam numa posição privilegiada de acumulação e dominação.

Os engenhos, em particular os engenhos exportadores (1) de Porto Alegre, Pelotas e Cachoeira, eram o principal centro de acumulação do capital arrozeiro. Sendo financiadores, industrializadores e comerciantes da produção, a eles se submetiam necessariamente os plantadores. Particularmente através do

adiantamento" de dinheiro, o engenho obriga o plantador a lhe entregar todo o arroz colhido, o que implicava em possibilidades de auferir parte dos lucros do plantador e, ao mesmo tempo, garantia para si o arroz e seus lucros industriais e comerciais na concorrência com os outros engenhos.

Os fazendeiros participavam da nova riqueza através do arrendamento e da parceria. Secundariamente, eles eram empresários diretos da produção. Provavelmente, a metade da produção realizava-se em terras arrendadas em percentagem da colheita e isto pesava negativamente tanto no custo do cereal como nas possibilidades de lucro e cálculo capitalista do produtor, deprimindo o desenvolvimento das forças produtivas.

A maior parte da produção dava-se em grandes e médias empresas capitalistas, em cujo processo de produção predominava o trabalho vivo não mecanizado (2). Dentro destas empresas, destacam-se as enormes plantações próprias dos engenhos e as plantações de alguns grandes arrendatários mais ou menos dependentes dos engenhos. A pequena unidade produtora - até 9 ha - era numericamente maioritária, mas tinha importância reduzida no volume total da produção. Os objetivos e processo de trabalho são do tipo camponês (3) e, ao que tudo indica, engenhos e fazendeiros ficavam com todo o sobretrabalho do pequeno produtor.

A cultura caracterizava-se por um alto custo de produção não contestado e até estimulado pelos altos preços do período e pela estrutura econômica gaúcha. O crédito era caríssimo e a ele só tinham livre acesso os engenhos, o arrendamento onerava seriamente o custo e condicionava a racionalidade tecnológica e com ela o barateamento do produto. O transporte era deficiente e caríssimo (gravando o produto até $30 \%$ ), a ambalagem cara e produzida monopolisticamente em São Paulo, os impostos municipais e estaduais anacrônicos. A estrutura produtora possuía, contudo, uma tendência progressista: a acumulação capitalista nos engenhos e grandes arrendatários oferecia um caminho possivel no avanço do modo de produção capitalista a nível da lavoura. Precisamente quando, a partir de 1921, as bases da produção entram em crise, vere- 
mos os donos de engenho assumir a liderança e o controle sindical e político da situação.

Os preços do período da guerra terminam bruscamente em 1921, caindo num $40 \%$. Os gaúchos são desalojados em 1924 do mercado platino pelos concorrentes europeus. O mercado nacional é vantajosamente disputado por paulistas e mineiros, que estão melhor localizados geograficamente e produzem um arroz que se adapta mais ao padrão qualitativamente baixo do consumo nacional. Finalmente, em 1925 o Governo Federal, não podendo mais controlar o preço dos artigos de consumo popular, permite a importação de arroz. Em 1926, a crise estoura. $\mathrm{O}$ arroz gaúcho simplesmente não é comprado, e o preço fica por baixo do custo de produção.

Por iniciativa de um grupo de grandes comerciantes do produto, constitui-se o Sindicato Arrozeiro do Rio Grande do Sul. Um amplo debate se sucede entre os empresários; aparecem diferentes linhas de conduta que serão uma constante na década de 1930. Os plantadores insistem mais nos problemas de custo, e os engenhos e firmas exportadoras preocupam-se mais pela conquista de mercados, em especial os estrangeiros, e disciplinar a comercialização. Será esta última a linha predominante. O Sindicato resolve comprar o arroz e tomar medidas para assegurar um preço mínimo para o produto. Para tal, aceita o oferecimento de crédito da Bier e Ullmann, uma das maiores firmas comerciantes de Porto Alegre. A medida de compra do produto pelo Sindicato não foi necessária. Os comerciantes reativaram imediatamente as compras frente ao perigo de ficar fora do mercado, que, de fato, seria centralizado pela Bier e Ullmann com o amparo do Sindicato.

O Sindicato, presidido em toda sua história (desde 1926 até 1937) por Alberto Bins - arrozeiro de Gravataí, mas sobretudo homem chave da Associação Comercial de Porto Alegre e posteriormente também do Centro de Indústria Fabril do Rio Grande do Sul, prefeito da ciđade entre 1928 e 1937 e destacado lider político - , pede e recebe imediatamente o auxílio do governo estadual, então nas mãos de Borges de Medeiros. Em 1926, o governo isenta de taxas da exportação. Em 1927, o Sindicato é legalmente autorizado a realizar a classificação do arroz exportado e, para tal, cobra uma Taxa de Expediente. Também o Sindicato pode aplicar uma Taxa de Defesa, que onerava o arroz exportado para portos nacionais e cuja arrecadação era utilizada em prêmios aos exportadores para portos estrangeiros, onde o arroz chegaria assim mais barato e competitivo. Todas as taxas tinham caráter obrigatório. A Taxa de Defesa, que fora utilizada em 1929 e 1930, implicava numa redistribuição dos lucros a favor dos exportadores: tanto os interesses dos plantadores como as intenções do governo de barateamento do produto no mercado nacional eram prejudicados. Em 1928, o Sindicato importa as sementes de arroz "Blue Rosen e "Long Edith" e as distribui gratuitamente com a obrigação de receber o triplo depois da colheita. Tenta-se com isso produzir um arroz que possa enfrentar no Prata e na Europa a concorrência italiana, que era a mais importante.

3 - A REPÚBLICA NOVA: CONTINUIDADE E TRANSIÇÃO

\section{1 - A crise de 1931 e a ratificação dos rumos}


de safra. Mesmo com a aplicação de prêmios nesse ano, não foi possivel escoar todo o arroz produzido e, em fevereiro de 1931, havia um importante estoque que não tinha saida. No mercado nacional, os gaúchos tinham dificuldades de concorrência, como já vimos, com paulistas e mineiros. Fora do pais, como reflexo da crise mundial de 1929 , os preços tinham caído entre $30 \%$ e $40 \%$. Frente a essa situação do mercado, os engenhos não conseguem vender o estoque è, menos ainda, empréstimos nos bancos. Portanto, não podem adiantar dinheiro aos plantadores, e toda a colheita corre o risco de se perder. A ruina dos empresários e a desocupação de 30.000 trabalhadores preocupava a todos, desde os empresários até o governo.

O Sindicato reúne-se em fevereiro. Seguramente alentados pela ilusão de que em 1930 os gaúchos tinham ascendido ao poder político federal, os rizicultores decidem dar um passo à frente na obtenção de privilégios por parte do Estado: pedem que o governo federal estabeleça uma Taxa Nacional de Defesa. Todo o arroz brasileiro pagaria no mercado interno uma taxa cuja arrecadação seria utilizada nos prêmios de exportação. Frente à lógica oposição dos arrozeiros paulistas - que não exportavam - e dos industriais paulistas - que viam subir o preço do cereal -, o Presidente Vargas nega o pedido, mas faculta a Flores para que arranje nos bancos do Estado o dinheiro necessário para pôr em marcha a concessão de prêmios à exportação. $O$ empréstimo foi realizado e seria saldado pelo Sindicato com o obtido da Taxa de Defesa gaúcha, que gravava a exportação para portos nacionais. Em abril começa a exportação. São conquistadas 17 praças no estrangeiro, entre elas a do Rio da Prata, e o volume exportado atinge uma cifra recorde. Em julho, o Sindicato achou que podia suspender os prêmios, deixando o mercado à sua evolução natural. Também obteve o Sindicato a modificação da tabela de preços da praça do Rio de Janeiro, graças à intervenção de Lindolfo Collor frente ao prefeito daquela cidade (4).

Entretanto, correntes de oposição à linha adotada delineavam-se claramente. Em março, os engenhos de Cachoeira tentam formar um consórcio com financiamento próprio e independente do Sindicato. Frustrada essa iniciativa e iniciada a exportação com prêmios em abril, os engenhos cochoeirenses entram a barganhar, dentro do Sindicato, a concessão de prêmios. Ao mesmo tempo, alguns plantadores de Cachoeira e outros municípios colocam-se numa posição de crítica ao conjunto da política sindical. Em julho, quando o Sindicato fecha a concessão de prêmios, os engenhos de Cachoeira, Rio Parḍo e São Gabriel unem-se para protestar: vê-se que eles não tinham conseguido vender todo o arroz, a diferença dos de Porto Alegre e Pelotas. O protesto dos cachoeirenses adquire então um caráter político: em lugar de dirigir-se ao Sindicato, entrevistam Borges de Medeiros em Cachoeira e comunicam-se com Neves da Fontoura no Rio de Janeiro. Em prosseguimento, Borges fala com Flores e Bins e, por seu lado, os engenhos pressionam diretamente o Sindicato, que finalmente cede. O Sindicato obtém o visto de Vargas para receber um novo empréstimo, esta vez do Banco do Brasil, que serviria para comprar o arroz estocado. O governo estadual era o avalista do empréstimo.

A entrada do Sindicato no mercado é aprovada pela Assembléia anual do mesmo realizada em 29 de julho de 1931 , mas ela não foi finalmente necessária, porque, ante essa resolução, o mercado regularizou-se (5). 
No transcurso da crise de 1931, distinguem-se claramente duas grandes correntes entre os empresários arrozeiros: a dos partidários da permanência da estrutura da produção dominada pelos engenhos e firmas comerciais e a dos críticos dessa estrutura. Dentro do primeiro grupo, ainda, observam-se duas facções: por um lado, os engenhos, comerciantes e grandes plantadores de Porto Alegre e municipios vizinhos e, secundariamenté, de Pelotas; por outro, os engenhos e grandes plantadores da Cachoeira, apoiados pelos seus congêneres de outros municípios do interior do estado.

A curto prazo, o grupo de Porto Alegre propunha-se a pôr em marcha a estrutura produtora paralisada pela crise, de modo que ela fumcionasse tal como estava montada. Através dos prêmios à exportação para fora do país, proporcionava-se crédito, mercado e altos preços ao engenhos exportadores, que punham em funcionamento a lavoura por meio de adiantamentos de dinheiro. Dessa maneira, os engenhos confirmavam sua dominação sobre a lavoura e obviavam a concorrência com São Paulo. Em julho, este grupo tinha aparentemente vendido seu arroz; daí que o Sindicato considerasse fechada a concessão de prêmios.

A longo prazo, p grupo queria racionalizar a produção e a comercialização: produzir um artigo mais barato, de primeira qualidade e perfeitamente tipificado, capaz de concorrer exitosamente no mercado internacional. Para tal, havia que plantar o "Blue Rose», selecionar a semente, adubar e mecanizar para colher cedo. Quem não pudesse atingir isto, melhor que não plantasse. Também era necessária uma radical revisão da política impositiva estadual (6), a redução dos fretes - em especial os marítimos - e a construção de estradas.

O Estado e o Sindicato não deviam ocupar o lugar dos produtores e comerciantes, mas unicamente viabilizar seus negócios facilitando mercados, financiamento e informações técnicas. Aos produtores correspondia decidir, através do Sindicato, assuntos chave, como os salários dos trabalhadores e o preço do produto.

Este grupo de empresários de Porto Alegre e municipios vizinhos tinha condições excepcionais de acumulação graças à Renda Diferencial, que sua localização geográfica e uma acumulação inicial superior the proporcionavam. Entretanto, também era forte porque, junto ao seu poder econômico e sindical, soube ocupar um importante espaço no poder político estadual e federal e, desse modo, legalizar sua atuação.

Os integrantes deste grupo mantêm a liderança dentro do Sindicato entre 1926 e 1937. Entre eles, destacam-se, além de Bins: Gastão Englert, da Bier e Ullmann, depois Bier e Englert - uma das maiores firmas comerciantes de arroz -; Vitor Kessler, da Arrozeira Brasileira - a maior potência produtora (com lavouras em Tapes, Guaiba, etc., e engenho em Porto Alegre) e exportadora do estado e importante industrial -; Francisco Berta, vinculado ao exportador José Berta, que ocupava os primeiros lugares depois da Arrozeira Brasileira; Ismael Chaves Barcellos, grande plantador em Tapes, que fundaria a Guaíba Arroz na década de 1949 e co-proprietário do Lanifício São Pedro; Adolfo Trein e Walter Schmidt, que, junto a Englert, destacavam-se por sua 
ampla visão da comerciàlização - o primeiro provavelmente ligado a Raabe, outro dos maiores exportadores.

Esse grupo mantinha excelentes relações com o Interventor Federal, de quem obteve completo apoio. Em particular, Bins e Kessler participavam ativamente em política, sendo o primeiro titular e o segundo suplente da Comissão Diretora do partido da situação, o Partido Republicano Liberal (PRL). Também foram boas as relações do Sindicato (e, portanto, do grupo) com o Governo Federal em 1931 e mesmo depois. Isso é facilmente explicável. Nos anos posteriores à Revolução de 1930, por razões econômicas e políticas, era necessário restabelecer todas as produções sem exceção, e era importantíssimo exportar. Como vimos, Vargas conseguiu atender às reclamações dos gaúchos sem ferir os interesses dos arrozeiros e industriais paulistas. Mais adiante, veremos que, à medida que avançamos na República Nova, isso seria cada vez mais difícil, manifestando-se drasticamente a contradição em 1937, com a transformação do Sindicato em Instituto e a perda da liderança por parte do grupo.

Em oposição ao grupo dirigente do Sindicato, aparecem os donos de engenho de Cachoeira. Estes não divergiam quanto à essência do programa dos primeiros. Sua discrepância devia-se a que usufruíam menos lucros tanto por razões de localização geográfica quanto pelo fato de não ter em suas mãos o poder sindical, apelava para outras soluções sucessivamente frustadas liderança sindical, apelava para outras soluções sucessivamente frustradas consórcio, brigar por uma distribuição mais eqüitativa dos prêmios, insistir no barateamento dos fretes ferroviários e fluviais, etc. Não obtendo seus objetivos senão parcialmente, o grupo exigia a intervenção direta do Estado ou do Sindicato na comercialização, esperando, desse modo, tirar do caminho os intermediários de Porto Alegre e emparelhar as situações. Na verdade, diziam eles, a aparente neutralidade do Sindicato e a permanente tentativa do grupo dirigente por mantê-lo fora do mercado, ou delimitar claramente sua atuação, escondia o verdadeiro objetivo do grupo de Porto Alegre, a saber, que o Sindicato não os substituísse nos seus negócios particulares, mas que, precisamente, os assegurasse em prejuizo dos empresários do resto do estado.

Em julho de 1931, como já vimos, os donos de engenho de Cachoeira, vendo-se prejudicados pela suspensão dos prêmios, partiram para a ação política. Sintomaticamente, não se dirigiram ao Interventor ou ao Presidente da República, mas a Borges, chefe do Partido Republicano Rio-grandense (PRR) e a Neves da Fontoura, já então liderando a oposição nacional a Vargas. Todo este episódio, que termina quando Vargas ordena ao Banco do Brasil a concessão de um empréstimo ao Sindicato para comprar o arroz estocado em Cachoeira e outros municípios, é extremamente singnificativo do que estava acontecendo em 1931, um ano antes da contra-revolução de 1932: a Frente Única Gaúcha (FUG) unida, mas já com os germes da dissolução, luta dentro da categoria arrozeira, expressando a disputa econômica a nível político e, finalmente, a conciliação. No decisivo ano de 1932 , depois da derrota da contra-revolução, parece ocorrer uma arrefecimento das discrepâncias, que se manteria até o fim da República Nova. O prefeito de Cachoeira Leopoldo de Souza - arrozeiro e destacado líder local do PRR - é substituido por Aldomiro Franco, do PRL, sem ligações importantes visiveis com o modo arrozeiro. Ao mesmo tem- 
po, os empresários arrozeiros mais influentes de Cachoeira inclinavam-se para o PRR, local cujo diretório é totalmente ocupado por eles.

Manifestava-se ainda, dentro do Sindicato, outra corrente de opinião expressando o ponto de vista dos críticos da estrutura produtora arrozeira. Afirmavam estes que o Sindicato atuava em exclusivo benefício dos engenhos exportadores, que a política de prêmios era um ônus para os lavoureiros e não resolvia, mas agravava a situação, via valorização do produto. A ordem do dia era baixar os custos e produzir só arroz de primeira qualidade, única maneira de ter competividade no estrangeiro - e enquanto isso não fosse atingido, era necessário deter o crescimento do volume da produção. Para tal, era preciso reformular as relações engenho-lavoura, substituindo os "adiantamento" por crédito barato e a longo prazo e "warrantagem». Ao Estado correspondia intervir diretamente, financiando e abrindo mercados; legislando sobre a propriedade da terra e atualizando o código de águas de modo a racionalizar a irrigação e diminuir o ônus do arrendamento; barateando os fretes; reformulando o sistema impositivo; criando Estações Experimentais que melhorassem a tecnologia a empregar e fixando salários e preços para o produto.

Esta corrente, que expressava os interesses dos grandes e médios plantadores capitalistas que tinham conseguido ou pretendiam uma certa independência dos engenhos, não teria uma expressão política própria em 1931 e, em várias oportunidades, une-se ao grupo de Cachoeira na oposição à direção sindical. Seu poder parece haver crescido bastante nas décadas de 1930 e $1940-$ particularmente a partir do Congresso de Cachoeira de 1940, mediante o qual conseguem real influência no futuro IRGA. Muitas decisões do IRGA e do Estado os beneficiarão.

\section{2 - Significado e Resultados da Política Adotada}

A orientação sindical triunfante em 1931 - que era praticamente a mesma que a do periodo 1926-1930 - terminou de afirmar-se depois de ter demonstrado, na prática, que viabilizava a acumulação de capital dos empresários arrozeiros. Se bem que essa orientação fosse contestada por aqueles que acumulavam menos, de fato ela permitiu salvar as bases em que estava montada a cultura do cereal.

Assim, essa linha de atuação aparentemente não sofreu novos baques até 1937. Em 1932, a situação da comercialização era boa, uma vez que a exportação recorde de 1931 não deixava um estoque de importância. Quando, em julho desse ano, o mercado ameaça uma retração, o Sindicato forma o Departamento Comercial e este estabelece uma tabela minima de preços a serem respeitados, sob pena de entrar o Sindicato a comprar ele mesmo o cereal. Junto a esse tipo de medidas, que se tornam permanentes controles da comercialização, ocorre uma melhora paulatina mas firme da demanda nos mercados nacional e platino, o que faz com que o Sindicato não precise praticamente intervir no mercado até sua liquidação, em 1937.

Quanto à estrutura produtora e comercializadora do arroz, o período da República Nova parece ter sido uma etapa de concentração econômica. Com certeza, foi esta uma época de lucros excepcionalmente altos para os engenhos 
e comerciantes exportadores. $O$ dado mais expressivo disto é a entrada de capital estrangeiro neste ramo. Os precursores nisto foram os capitalistas italianos que, em sociedade com Kessler, fundaram, na década de 1920, a antecessora da Arrozeira Brasileira. Mas é ainda mais significativa a entrada jem 1935, da Brasil Arroz, filial de "Bunge and Born", no beneficiamento e comercialização (7).

A concentração manifestou-se a nivel dos engenhos, aumentando a distância entre os engenhos exportadores e os simplesmente beneficiadores, mas foi ainda decisivo a nivel da lavoura e da dominação do engenho sobre a lavoura. A percentagem de pequenos plantadores no total das firmas parece ter diminuído. Há indícios do desenvolvimento de lavouras de 20 ha ou 30 ha, ou seja, de lavouras capitalistas médias, as quais, na década de 1920, aparecem mais raramente. Estas lavouras encontram-se totalmente presas aos engenhos pelo sistema de "adiantamento". Finalmente, a tendência, já observada na década de 1920, à formação de grandes lavouras, muitas delas integradas aos engenhos exportadores, é a mais notável.

O aumento da importância relativa das grandes e médias empresas capitalistas liga-se à adoção de novos $\mid$ processos tecnológicos - seleção de sementes e adubação - e ao reforçamento do domínio direto da empresa - via limitação da atividade dos empreiteiros - sobre a organização e exploração da mão-de-obra assalariada.

Em geral, toda a política trabalhista da República Nova de repressão e cooptação dos trabalhadores e, em particular, a fixação pelo Sindicato do salário e as normas que regiam as relaçōes de produção, diminuía as possibilidades de concorrência pela mão-de-obra entre os empresários e pressionava o nível dos salários para baixo numa época de abundância relativa de mão-de-obra, onde chega a ocorrer a ida do trabalhador da cidade para o campo.A mais-valia assim assegurada - unida ao sobretrabalho do pequeno produtor, agora com menos condições que antes de se defender devido à paulatina mudança do padrão tecnológico - concentrava-se primeiro nas empresas plantadoras, e fluía depois em proporção importante para os fazendeiros arrendadores e os engenhos exportadores.

Esta concentração econômica é obra do momento critico que se passava, que acentuava a tendência estrutural à acumulação de capital, mas também, e fundamentalmente, da atuação politica e sindical dos grandes empresários e a correspondente política governamental.

Como resultado deste processo, entre 1926 e 1937 o volume de produção mantém-se estacionário, havendo, contudo, mudanças de qualidade - abandono paulatino do "agulha", predominio do «japonês" e o "Blue Rose", destinados à exportação para o estrangeiro. $\mathrm{O}$ mercado local de consumo,que fora mais importante que o nacional e quase tão importante como o platino até 1924 , reduz seu peso a $10 \%$ do arroz beneficiado. Quem aparece triunfante é o mercado nacional. Apesar dos esforços do Sindicato na colocação do arroz no estrangeiro, entre 1926 e 1937 predomina a exportação para portos nacionais - com exceção de 1931 e 1935 . Em 1936 e 1937, este fenômeno acentua-se claramente. As exportações crescem em $50 \%$ em relação aos anos anteriores, e a exportação 
para portos nacionais é duas a três vezes superior à dirigida para o estrangeiro. A rizicultura gaúcha tinha sido incorporada ao mercado interno brasileiro agora dominado pela indústria paulista, e isso não passaria ao nível sindical e politico.

\section{3 - 1937: A Nova Política}

Em novembro de 1937, ocorre o golpe que põe fim à República Nova. Flores foge para o Uruguai. Bins, apesar de sua renúncia ao PRL e sua declarada adesão a Vargas e à doutrina do governo forte, não pode evitar a queda e até é publicamente acusado de fraude. No mesmo mês, o Dr. Maurício Cardoso, homem do PRR que tinha subido ao cargo de Secretário do Estado junto com outros do seu grupo e da dissidência do PRL, baixa uma portaria criticando duramente a situação, a seu juizo inconstitucional, de que o Sindicato Arrozeiro, uma instituição privada, cobrasse taxas e tivesse poderes que só o Estado podia ter.

Abre-se o período mais confuso da vida do Sindicato. Os jornais não o registram, mas parece ter havido uma reunião do Sindicato que, apressadamente, pediu a transformação do mesmo em Instituto, de modo a manter os poderes, superando-se a inconstitucionalidade. Em dezembro, contudo, a resposta do Governo Estadual é anular todas as disposições legais que permitiam ao agora Instituto do Arroz cobrar taxas e outorgar prêmios. O silêncio dos jornais mantém-se até abril de 1938, em que o novo Interventor Cordeiro de Farias, pelo Decreto $\mathrm{n}^{\circ} 7.220$, de 13 de abril de 1938 , legaliza o Instituto, iniciando o processo de criação do IRGA. O major Cacildo Krebs - grande plantador do município de Guaíba, colega de Escola Militar de Góes Monteiro e dos tenentes da década de 1920 e homem estreitamente ligado a Vargas - é nomeado, em algum momento, presidente do Instituto e nesse cargo continuará por mais de uma década.

Dois dos considerandos do Decreto $\mathrm{n}^{\circ} 7.220$ do Interventor Federal são bem significativos:

(...) Considerando que o Instituto (...) vive presentemente da exclusiva contribuição de seus associados e por esse motivo precisa da intervenção do Estado para atender eficientemente seus objetivos, com maior proveito para a economia daquele;

Considerando que a intervenção do Etado no dominio econômico só se legitima para suprir as deficiências da iniciativa particular (...), de maneira a evitar ou resolver os seus conflitos e introduzir no jogo das competiçes individuais o pensamento dos interesses da naçăo, representados pelo Estado (...)

Assim, o Instituto poderá arrecadar a taxa de exportação, ficando a seu cargo a classificação do arroz, mas $70 \%$ dessa taxa será aplicada na criação e manutenção de Estações Experimentais, e o Instituto apresentará, mensalmente, às Secretarias de Agricultura e Fazenda, um balancete demonstrativo da arrecadação e aplicação da taxa e ficará subordinado à orientação da primeira daquelas Secretarias no que diz respeito ao fomento da produção rizícola. 
Agreguemos a isso o lema que guiou a administração do major Krebs: «Baratear por todos os meios a produção!n e teremos um panorama sintético das implicações da mudança de 1937-1938.

A rizicultura gaúcha, junto à sua função exportadora, ganhou outra mais importante: proporcionar alimentação barata de modo a reduzir o custo de reprodução da mão-de-obra industrial, contribuindo assim à maximização da acumulação na indústria. O controle da direção do processo pelo Estado e a correspodente formalização da dominação econômica e política da burguesia industrial paulista adquirem agora nova consistência. Já não seria tão fácil fazer o jogo da alta dos preços e dar superlucros aos exportadores e arrozeiros rio-grandenses. O regionalismo gaúcho sofria um golpe importante. A autarquia tentará orientar a produção de maneira cada vez mais firme e segura para uma racionalização capitalista ao serviço dos lucros da burguesia industrial.

\section{4- CONCLUSÃO}

O periodo da República Nova, se observado desde o ângulo da produção arrozeira, aparece como um periodo de transição.

As transformações políticas e econômicas viabilizadas pela Revolução de 1930 - concretamente, a transição do modelo capitalista agroexportador para o modelo centrado na acumulação industrial - por um lado, abrem aos rizicultores gaúchos um espaço político e econômico ainda maior que o que tinham na República Velha, permitindo com isso a.continuidade e a consolidação das formas de acumulação do capital já esboçadas.

Por outro lado, essas mesmas transformações criam as condições para a subordinação deste capitalismo agrário periférico aos interesses maiores da agora dominante acumulação industrial. A rápida mudança da situação em 1937 foi preparada durante todo o periodo e põe isso em evidência. Dali em diante, a agricultura capitalista gaúcha seria crescentemente disciplinada e racionalizada peloEstado, que assume os interesses da burguesia industrial do centro.

Isto não significaria, contudo, o fim do capitalismo agrário gaúcho e da atuação política e sindical dos empresários. Pelo contrário, se bem que de maneira subordinada, ficava novamente garantida sua continuidade, de modo tal que o desenvolvimento das forças produtivas e a submissão real do trabalho ao capital atingiriam ainda um nível superior.

\section{NOTAS}

(1) EStes eram, já na década de 1920, verdadeiras fábricas totalmente mecanizadas, utilizando, em alguns casos, a tecnologia mais avançada do mundo.

(2) Nestas empresas, o processo deproduçåo, do ponto de vista tecnológico, era realizado como antes nas unidades coloniais, exceção feita da irrigação e atrilha, que esta- 
vam mecanizadas. A adubação $\Theta$ a seleção de sementes eram raramente utilizadas. Contudo, a escala e objetivos da produção, a situação dos trabalhadores que seriam maioritariamente despossuidos dos meios de produção - $\theta$ a organização tendente a intensificar $\Theta$ alongar ao máximo a jornada de trabalho, permitem que qualificamos o processo de trabalho no seu conjunto como sendo capitalista na fase de submissão formal do trabalho ao capital (mais valia absoluta).

(3) Mão-de-obra familiar e cultura de subsistência ao lado da comercial do arroz, objetivando à sobrevivência pura e simples da familia.

(4) A tabela, que antes favorecia as qualidades de arroz produzidas em São Paulo, é parcialmente modificada em beneficio dos rio-grandenses.

(5) Em realidade, năo seria o Sindicato que entraria a comprar diretamente. Os comerciantes seriam considerados da seguinte maneira: formar-se-iam em cada lugar cooperativas de engenhos e plantadores, que receberiam o dinheiro do Sindicato para comprar o arroz e a ele deviam prestar contas. Nesta oportunidade, quem recebia a ajuda năo eram os engenhos e comerciantes de Porto Alegre, que já tinham vendido o arroz, mas os do interior. Os de Porto Alegre perdiam sim a possibilidade de lucrar com as dificuldades dos do interior. Provavelmente por isso o mercado regularizouse de imediato.

(6) Forte aumento dos impostos aos proprietários de terras improdutivas, supressão dosimpostos de exportação municipais e estaduais e de importação de máquinas e matérias primas - como a juta para os sacos de arrosz.

(7) Por sinal, a Brasil Arroz colocou-se logo no ápice da exportação, ocupando o $3^{\circ}$ e $4^{\circ}$ lugar em 1935 e 1937, respectivamente.

\section{5 - BIBLIOGRAFIA}

AROZTEGUI, Ema Julia M. A lavoura arrozeira rio-grandense nas três primeiras décadas do século XX. Porto Alegre, UFRGS, 1980. (Dissertação de bacharelado).

BASTOS, Aristarcho M. Efemérides. In: Lavoura Arrozeira. Porto Alegre, IRGA, 1964, 1965, 1966, 1967.

BURGER, Ary. As flutuações na economia orizicola do Rio Grande do Sul. Porto Alegre, Ética Impressora, 1955.

COSTA, Alfredo R. da. O Rio Grande do Sul. Porto Alegre, Globo, 1922.

COSTA, Renato. A produção e as exportaçōes de arroz no Rio Grande do Sul. In: Digesto Econômico. n. 21. São Paulo, ag. 1946.

FAUSEL, Erich. Alberto Bins, o merlense brasileiro. Porto Alegre, Rotermund \& Cia., 1963.

PIMENTEL, Fortunato, Aspectos da cultura do arroz no Rio Grande do sul. Porto Alegre, IRGA, 1949.

ROCHE, Jean. A colonização alemã e o Rio Grande do Sul. Porto Alegre, Globo, 1969.

SINDICATO ARROZEIRO do RIo Grande do Sul. A cultura do arroz. Porto Alegre, Tipografia Mercantil, 1935.

RELATÓRIOS dos Governadores do Estado do Rio Grande do Sul. 1920 a 1937.

ANAIS da Assembléia do Estado do Rio Grande do Sul, 1935 a 1937.

LEIS, Decretos e Atos do Governo do EStado do Rio Grande do Sul. 1927 a 1938.

CORREIO DO POVO. Porto Alegre, jun.-ago. 1926; out. 1930; abr. 1938.

DIÁRIO DE NOTÍCIAS. Porto Alegre, mar.-jul. 1926; nov. 1937.

ANUÁRIO da Produção Agropecuária do Rio Grande do Sul. Porto Alegre, DEE, 1965 e 1967.

O BRASIL em números. Apêndice do Anuário Estatístico do Brasil, 1960. Rio de Janeiro, IBGE, 1960.

ANUÁRIO do Rio Grande do Sul, n. 9 Ministério do Trabalho, Indústria e Comércio, 1940.

ONZE entrevistas a comerciantes, donos de engenho e plantadores, que participaram direta ou indiretamente dos fatos. 